\title{
The future direction of the Dental Public Health in Malaysia
}

Muhd Firdaus Che Musa*

Kulliyyah of Dentistry, International Islamic University Malaysia, Department of Paediatric Dentistry and DPH, Pahang, Malaysia

\begin{abstract}
The continued recognition of Dental Public Health as one speciality in dentistry provides an opportunity for the speciality to rediscover and reevaluate itself. As a discipline, public health dentistry evolved for many years to address the issues faced by our dynamic society, particularly Malaysia. Increased investment is necessary to see a tangible improvement in oral health. In this light, public health dentistry represents the nation's dental conscience, as changes in DPH mirror both changes in society and the dental practice. Prevention and access to dental care for the underprivileged groups are as pertinent as providing medical and dental care for people with infectious diseases. Changes could be implemented through national oral health objectives and strategies and a myriad of new financing mechanisms. Despite the progressive changes in today's world, the speciality's goal to improve the public's oral health and its commitment to work through 'organised community efforts' to achieve this goal remains. This article highlights the need for a long-term solution that could ensure the sustainability of DPH in Malaysia. It empowers DPH specialists to use their expertise for patients' benefit across the three pillars of public health - health improvement, care, and protection. This could be achieved through the support of the dental community.
\end{abstract}

Keywords: community, dentistry, Dental Public Health, Malaysia specialist
Received:

10 February 2022

Revised:

27 February 2022

Accepted:

28 February 2022

Published Online:

4 March 2022

How to cite this article:

Che Musa, M. F. The future direction of the Dental Public Health in Malaysia. IIUM Journal of Orofacial and Health Sciences, 3(1), 153-155 https://doi.org/10.31436/ijoh s.v3i1.127

\section{Article DOI:}

10.31436/ijohs.v3i1.127

*Corresponding author

Address:

Department of Paediatric

Dentistry and DPH

Kulliyyah of Dentistry,

International Islamic University

Malaysia,

25200 Kuantan, Pahang,

Malaysia

Telephone: +609-5705489

Email address:

muhdfirdaus@iium.edu.my

\section{Introduction}

Undoubtedly, 2020 has been an unforgettable, challenging year for everyone across the globe. The emergence the highly contagious SARS-CoV-2 coronavirus in 2019 (Sakurai et al., 2020) has shaken the world to its core. The whole world stood still as lockdowns were enforced to curb the spread of the virus. Covid-19 related lockdowns and restrictions have had a significant impacts on a country's economy as well as people's social and emotional well-being (Duke Global Health Institute, 2020). As the saying goes, pandemics are lived forward and understood backwards. This statement reflects the situation during the COVID-19 pandemic where the public and dental professionals grapple with the reality of

living with COVID-19 restrictions (Che Musa et al., 2021b; Epstein et al., 2020). The profession is facing critical challenges to spread health promotion messages to the public more than ever. In this regard, there are concerns over what the future holds for dentistry and Dental Public Health (DPH) in particular.

In addition, the pandemic significantly affects patients and dental professionals (Guo et al., 2020). Studies also found that oral health inequalities have increased during the pandemic due to economic and social restrictions (Marmot, 2020; Watt, 2020). Based on current demands (Ahmadi 
et al., 2020; Epstein et al., 2020), there is a need to explore sustainable ways for dental professionals to embrace the new norms. Such initiative could help convince the public and encourage them to seek high quality, safe dental care (Passarelli et al., 2020; Watt, 2020).

DPH focuses on preventing and promoting oral health (Chesnutt, 2016) plays a significant role in ensuring access to dental health. The DPH ecosystem was working successfully before pandemic. This is evident in the success of DPH teams in disseminating dental agenda in Malaysia (Oral Health Division Malaysia, 2011; Oral Health Programme Malaysia, 2019), as it has provided significant input in improving access to dental care. To achieve and maintain these goals, DPH personnel must be skilled in various areas, such as population-based oral health planning, therapies and methods for oral disease prevention and control, as well as oral health promotion (Hiremath, 2007; Patel et al., 2018). As DPH offers independent support and assistance to organisations throughout the health and social care system, it must be retained to guarantee that patient needs are fulfilled and acknowledged, and the population oral health is prioritised. Thus, DPH leadership and expertise are an essential component of the equation in improving population oral health and reducing oral health inequalities. While the linkages between oral and general health are well documented and understood within the dentistry community, there is much to done to ensure the proper integration of oral care into general patient care.

Influencing the broader social determinants of health is another crucial role for DPH, as to recognise the impact of adverse socioeconomic and environmental circumstances to poor oral health outcomes (Che Musa et al., 2020). Such impact is linked to climate change and the dental profession needs to evaluate how dental public care could be more sustainable to fulfil the aspiration of the Ministry of Health based on their report in 2018 and 2020 (Ministry of Health Malaysia, 2018, 2020).
Moreover, this speciality is also responsible in setting the potential budget on public health and for prioritising disease preventive measures and health improvement at the local, regional, and national levels. In this light, higher investment is required to achieve measurable improvements in oral health for Malaysia (Che Musa et al., 2021a). Funding could be channelled to local governments, which have legislative responsibility for health improvement to ensure health promotion programmes could be done with sufficient and sustainable. Moreover, it is necessary to increase dental health programmes' reach, engagement and impact to communities. Oral health improvement programmes such as community water fluoridation and tooth brushing supervision with fluoridated toothpaste should be intensified to emphasise the importance of dental health care among the public. It is a notion that needs to be spread through by all means necessary (Che Musa, 2017).

The DPH speciality also among other dental specialist's disciplines that experiences such regular upheaval. Hence, this speciality requires a long-term solution which allows this speciality to become sustainable and provide adequate dental care to the population health across the three pillars of public health - health improvement, healthcare public health, and health protection. Changes could be implemented through national oral health objectives and strategies and a myriad of new financing mechanisms. Despite the progressive changes in today's world, the speciality's goal to improve the public's oral health and its commitment to work through 'organised community efforts' to achieve this goal remains. It is hoped that, DPH specialists and other health professionals in Malaysia will have a solid and secure platform to work from in the future and that DPH workforce will receive the necessary support and funding from each relevant organisation.

\section{References}

Ahmadi, H., Ebrahimi, A., Ghorbani, F. (2020). The impact of COVID-19 pandemic on dental practice in Iran: a questionnaire-based report. BMC Oral 
Health, 20(1), 354. doi:10.1186/s12903-02001341-x

Che Musa, M. F. (2017). Malaysia healthcare system. Journal of Biotechnology and Strategic Health Research, 2(3), 7-10.

Che Musa, M. F., Ab Halim, N., Sayed Kamar, S. H., Abllah, Z., Supa'at, S., Mohd Ibrahim, M. S. (2021a). Current concept of oral health and its potential implications for policy and practice of dental health coverage and insurance: post COVID-19 measurement. IIUM Journal of Orofacial and Health Sciences, 2(1), 4-13.

Che Musa, M. F., Bernabe, E., Gallagher, J. E. (2020). The dental workforce in Malaysia: drivers for change from the perspectives of key stakeholders. International Dental Journal, 70(5), 360-373.

Che Musa, M. F., Sayed Kamar, S. H., Hassan, Y. F. (2021b). Living With COVID-19 is a reality among dental fraternity: a refection. Journal of Biotechnology and Strategic Health Research, 5(1).

Chesnutt, I. G. (2016). Dental Public Health at a Glance. Oxford, England: Wiley Blackwall.

Duke Global Health Institute. (2020). Will low-income countries be left behind when COVID-19 Vaccines Arrive? Retrieved from https://globalhealth.duke.edu/news/will-lowincome-countries-be-left-behind-when-covid-19vaccines-arrive

Epstein, J. B., Chow, K., Mathias, R. (2020). Dental procedure aerosols and COVID-19. The Lancet: Infectious Diseases, 1.

Guo, H., Zhou, Y., Liu, X., Tan, J. (2020). The impact of the COVID-19 epidemic on the utilization of emergency dental services. Journal of Dental Sciences.

Hiremath, S. S. (2007). Textbook of Preventive and Community Dentistry. New Delhi: Elsevier Publication.

Marmot, M. (2020). Society and the slow burn of inequality. Lancet, 395(10234), 1413-1414.

Ministry of Health Malaysia. (2018). Annual Report: Ministry of Health Malaysia 2018. Retrieved from Putrajaya:

Ministry of Health Malaysia. (2020). National Health and Morbidity Survey 2019 (fact Sheet): Noncommunicable diseases, healthcare demand and health literacy. Retrieved from Shah Alam: http://iku.moh.gov.my/images/IKU/Document/R EPORT/NHMS2019/Fact Sheet NHMS 2019English.pdf

Oral Health Division Malaysia. (2011). National Oral Health Plan for Malaysia 2011-2020. Retrieved from Putrajaya: http://www.moh.gov.my/

Oral Health Programme Malaysia. (2019). Annual Report 2018. Retrieved from Putrajaya: http://ohd.moh.gov.my/images/pdf/annual_rpt/ annual rpt18.pdf

Passarelli, P. C., Rella, E., Manicone, P. F., Garcia-Godoy, F., D'Addona, A. (2020). The impact of the COVID19 infection in dentistry. Experimental Biology and Medicine (Maywood), 245(11), 940-944.

Patel, R., Witton, R., Potterton, R., Smith, W., Kaimi, I. (2018). Dental Public Health in Action: Understanding oral health care needs and oral health-related quality of life in vulnerable adults in Plymouth. Community Dent Health, 35(4), 197-200.
Sakurai, A., Sasaki, T., Kato, S., Hayashi, M., Tsuzuki, S. I., Ishihara, T., et al. (2020). Natural History of Asymptomatic SARS-CoV-2 Infection. The New England Journal of Medicine, 383(9), 885-886.

Watt, R. G. (2020). COVID-19 is an opportunity for reform in dentistry. The Lancet, 396, 462. 